\title{
NMR Structures and Orientation of the Fourth Transmembrane Domain of the Rat Divalent Metal Transporter (DMT1) with G185D Mutation in SDS Micelles
}

\author{
Hongyan Li, Fei Li, Miufan Kwan, Qing-Yu He ${ }^{*}$ and Hongzhe Sun ${ }^{*}$ \\ Department of Chemistry and Open Laboratory of Chemical Biology, the University of Hong Kong, Pokfulam \\ Road, Hong Kong
}

\footnotetext{
*Correspondence to: Hongzhe Sun; e-mail: hsun@hkucc.hku.hk Abbreviations: DMT1, divalent metal transporter; NOESY, two dimensional nuclear Overhause effect spectroscopy; Nramp, natural resistance associated macrophage protein; SDS, sodium dodecyl sulfate; TOCSY, total correlation spectroscopy.
} 


\section{Abstract}

DMT1, also known as Nramp2, is an iron transporter, and belongs to the family of Nramp proteins. Disease-causing mutations both in Nrampl and Nramp2 occurring at the conserved two adjacent glycine residues located within the fourth transmembrane domain (TM4) suggest that TM4 may serve an important biological function. In the present study, we have determined the high-resolution structures of a synthetic peptide, corresponding to the sequence of the fourth transmembrane domain of rat DMT1 with G185D mutation, in membrane-mimetic environments (e.g. SDS micelles) using NMR spectroscopy and distance-geometry/simulated annealing calculations. The spatial structures showed $\alpha$-helices without kink in the middle portion of the peptide, with highly flexible and poorly defined N-terminus. Both the N-terminus and helical core of the peptide were embedded into the SDS micelles. Interestingly, the folding and membrane location of the C-terminus was pH-dependent, being well-folded and inserted into SDS micelles only at a low pH value (4.0). The peptide exhibited amphipathic characteristics, with hydrophilic residues (Asp7, Thr11, Asp14 and Thr15) lying in one side of the helix which provide a basis for the formation of water-filled channel architectures through self-associations. The significant broadening of the resonances of the hydrophilic residues Asp7,

Thr11, Asp14 which are buried inside SDS micelles, upon addition of $\mathrm{Mn}^{2+}$ further verified the possibility of the formation of a channel through which metal ions pass. The substitution of Gly7 by an aspartate residue neither significantly altered the structure and membrane location of the peptide nor abolished its properties of channel-forming and metal permeation compared with the wild-type peptide.

Key words: CD, DMT1; transmembrane peptide; micelle; NMR 


\section{INTRODUCTION}

The divalent metal transporter (DMT1), also known as Nramp2, is the first mammalian transmembrane iron transporter that actively transports reduced dietary iron into intestinal enterocytes and also transports iron across the membrane of acidified endosomes in pheripheral tissues. ${ }^{1-4}$ It is an integral membrane protein formed by 12 putative transmembrane domains, several of which contain charged residues. It belongs to the family of Nramp proteins highly conserved from bacteria to human beings, ${ }^{1,2}$ and shares $78 \%$ sequence identity in the hydrophobic core with Nramp1, a protein involved in defense against intracellular pathogens. ${ }^{2}$ Functional studies in Xenopus lavis oocytes and cultured mammalian cells have shown that DMT1 is an electrogenic transporter of divalent metal ions (including $\mathrm{Fe}^{2+}, \mathrm{Zn}^{2+}$ and $\mathrm{Mn}^{2+}$ ), and the transport appears to be dependent on $\mathrm{pH}$ and coupled to proton symport. ${ }^{1,5-7}$

Genetic studies in rodent models of iron deficiency and microcytic anemia have shown that the DMT1 gene is mutated (G185R) in the $m k$ mouse and in the Belgrade rat. ${ }^{2,8}$ Both animals exhibit severe iron deficiency anemia due to defects in intestinal iron transport and erythroid iron utilization. Transient expression studies in HEK293T cells have shown that DMT1 carrying the G185R mutant is severely function-impaired and cannot significantly stimulate iron uptake. ${ }^{5}$ Strikingly, naturally occurring mutation (G169D) in Nramp1 abrogates natural resistance to infection with intracellular parasites. ${ }^{9}$ Both disease-causing mutations occurred at the two adjacent glycine residues, conserved within the predicted transmembrane domain 4 of the proteins. This remarkably narrow spectrum of disease-causing mutation in Nramp proteins suggests that TM4 may serve a unique and important biological function.

There are serious obstacles in applying the most widely used methods for mimicking membrane protein structural studies. In particular, they are notoriously difficult to crystallize and multidimensional NMR methods are also hampered by the slow reorientation rate of proteins complexed with lipids. ${ }^{10}$ Detergent micelles have been established as well-accepted models for membrane environments. ${ }^{11}$ Fortunately, multidimensional solution NMR methods are feasible for the study of the structures of peptides and proteins in micelles, although the line-widths are five times broader than those in aqueous solution. Model peptides, corresponding to the sequence of functional 
domains or segments, have been demonstrated to be ideal objects for investigation of structure and function in several integral membrane proteins. ${ }^{12-18}$

There appears no prior knowledge on structure and assembly of integral DMT1. We have previously characterized the structures and membrane orientations and self-assembly of TM4 peptides for both the wild-type and the G185R mutant in membrane-mimetic SDS micelles. ${ }^{19,20}$ In the current study, the secondary structure of TM4 peptide with G185D mutation (G185D peptide) has been characterized in SDS micelles by CD and NMR spectroscopic techniques. The three-dimensional structures of the peptide bound to SDS at different $\mathrm{pH}$ values have been computed by molecular dynamics with simulated annealing calculations using the CYANA software package. ${ }^{21}$ Several homonuclear two-dimensional NMR techniques such as TOCSY ${ }^{22,23}$ and NOESY ${ }^{24,25}$ have been utilized to derive the complete proton resonance assignments. The interproton distances in threedimensional space were determined from the NOESY cross-peak intensities. The orientation of the peptide relative to SDS micellar surface was probed by the effects of paramagnetic agents, such as the 16-doxyl-stearic acid spin label and $\mathrm{Mn}^{2+}$, on the broadening of NMR resonances of the peptide. The peptide was embedded into the micelles with the C-termini exposed outside the micelles at $\mathrm{pH}$ 5.5. A possible assembly to form a water-filled channel through self-association was discussed.

\section{METHODS}

\section{Sample Preparation}

The sequence of the G185D peptide was taken from the $4^{\text {th }}$ transmembrane domain of rat DMT1 with a single point mutant, which was underlined $\left({ }^{179}\right.$ RVPLYGDVLITIADTFVFLFLDKY ${ }^{202}$ ). The G185D peptide was prepared by solid-phase synthesis and purified by HPLC on a Zorbax SB Phenyl reverse phase column using 0.1\% TFA/water and 0.1\% TFA/acetonitrile as solvents (Biopeptide CO. LLC. USA). Purity was evaluated by both HPLC and mass spectrometry to be above $95 \%$. All $\mathrm{D}_{2} \mathrm{O}$, SDS- $d_{25}$ and methonal- $d_{4}$ were purchased from Cambridge Isotopes Laboratories (MA). 1,1,1,3,3,3,-hexafluoro- 
2-propanol (HFIP), and 16-doxyl-stearic acid spin label were obtained from Sigma in the highest available purity and were used without further treatment.

The sample containing the G185D peptide in micellar solution was prepared using a previouslydescribed method. ${ }^{19}$ About $3.2 \mathrm{mg}$ of the peptide, dissolved in HFIP (or in $0.6 \mathrm{ml}$ TFE- $d_{2}$ for diffusion experiments), mixed with an equal volume of SDS- $d_{25}$ aqueous solution, and the mixture was further diluted with water to give rise to a 16: 1 ratio of water to HFIP and was subjected to lyophilization overnight. The resulting powder was dissolved in $0.6 \mathrm{ml}$ water (containing $10 \% \mathrm{D}_{2} \mathrm{O}$ ), which gave rise to ca. $2 \mathrm{mM}$ peptide and $300 \mathrm{mM}$ SDS- $d_{25}$. The $\mathrm{pH}$ values of the sample were adjusted by addition of $\mathrm{NaOH}$ or $\mathrm{HCl}$. The 16-doxyl-stearic acid was added as a solution in a least amount of methanol- $d_{4}$ to give a molar ratio of detergent to spin-label of 60: 1 . To measure the rate of deuterium exchange with amide protons, the peptide sample was lyophilized and dissolved in $\mathrm{D}_{2} \mathrm{O}, \mathrm{pH}^{*} 5.3$ (direct $\mathrm{pH}$-meter readings).

\section{Spectroscopy}

CD experiments were carried out on a Jasco-720 spectropolarimeter. All measurements were made at room temperature in a quartz cuvette of 1-mm path length. Spectra were recorded over the far-UV range of $190-260 \mathrm{~nm}$ with a time constant of $0.25 \mathrm{~s}$, a spectral resolution of $0.1 \mathrm{~nm}$, and a scan rate of $50 \mathrm{~nm} / \mathrm{min}$. Three scans were averaged for each spectrum, and the reference spectra of the respective media were subtracted. The peptide concentration for CD studies was $20 \mu \mathrm{M}$ and SDS of $50 \mathrm{mM}$. The helicity was estimated by both deconvolution of CD spectra using CDPro software ${ }^{26}$ and calculation using an empirical method described previously, on the assumption that the $[\theta]_{222}$ for $0 \%$ and $100 \% \alpha-$ helix contents were 2000 and $30000 \mathrm{deg} \mathrm{\textrm {cm } ^ { 2 } \mathrm { dmol } ^ { - 1 } \text { , respectively. }}{ }^{27,28}$

\section{NMR Spectroscopy}


The NMR experiments were performed at $298 \mathrm{~K}$ on a Bruker AV600 spectrometer. Two-dimensional NMR experiments were carried out in a phase sensitive mode using the States-TPPI ${ }^{29}$ for quadrature detection in the F1 dimension. Typically, 48-80 scans were collected with $2 \mathrm{~K}$ data points in F2 and 512 increments in F1 dimension. TOCSY experiments were performed with the MLEV-17 pulse ${ }^{30}$ with a spin-lock time of $100 \mathrm{~ms}$. NOESY spectra ${ }^{24,25}$ were acquired with mixing times of 50, 150, 200 and $250 \mathrm{~ms}$. Water signals were suppressed using WATERGATE. ${ }^{31,32}$ Chemical shifts were referenced by sodium salt of trimethylsilylpropionate $\left(\mathrm{TSP}-d_{4}\right)$.

The fast and slow exchanging amide protons were detected by a series of one-dimensional ${ }^{1} \mathrm{H}$ and two dimensional NOESY experiments (mixing time $200 \mathrm{~ms}$ ), recorded shortly after a lyophilized sample was dissolved in $\mathrm{D}_{2} \mathrm{O}$ at $\mathrm{pH}^{*} 5.3$ (direct meter reading). The effect of 16-doxyl-stearic acid on the NMR signals was monitored by recording NOESY spectra in the absence and presence of the spin label. Paramagnetic metal ion broadening studies were performed in the presence of $\mathrm{Mn}^{2+}$ at concentrations of $0.1,0.2$ and $1.0 \mathrm{mM}$ at pH 5.5 and 4.0. Similarly, the NOESY spectra (mixing time $200 \mathrm{~ms}$ ) were recorded before and after addition of $\mathrm{MnCl}_{2}$. The amplitudes of the spectra in the presence of 16-doxyl-stearic acid and paramagnetic metal ions were normalized to the least affected cross-peaks.

All NMR spectra were processed using standard Brüker software (XWINNMR Version 3.1). Prior to Fourier transform data were zero-filled to $2 \mathrm{~K}$ data points in $\mathrm{F} 1$ dimension and then transformed with a shifted sine-bell squared window function in both dimensions.

Diffusion coefficient measurements (diffusion ordered spectroscopy (DOSY) experiments) were performed on a Bruker DRX 500MHz spectrometer equipped with a z-axis gradient coil. The DOSY spectrum was acquired in a $5 \mathrm{~mm}$ sample tube at $25^{\circ} \mathrm{C}$. The gradient strength was calibrated using HDO signal in $\mathrm{D}_{2} \mathrm{O} .^{33}$ The stimulated echo bipolar pulse sequence using WATERGATE for water suppression was applied to the DOSY experiment. The diffusion time $(\Delta)$ of $250 \mathrm{~ms}$ was used in all 
experiments. The duration of the gradient pulse $(\delta)$ were 2.3 the peptide in order to obtain a $1-5 \%$ residual signal with the maximum gradient strength. After Fourier transformation and baseline correction, the diffusion dimension was processed with the two-exponential decays using the XWINNMR software. The apparent molecular mass (M) was calculated based on diffusion coefficient (D) assuming the peptides to be a prolate ellipsoid in TFE: ${ }^{34}$

$$
M=\left(k_{B} T / 6 \pi \eta F D\right)^{3}\left[4 \pi N_{A} /\left[3\left(v_{2}+\delta_{1} v_{1}\right)\right]\right]
$$

where $k_{\mathrm{B}}$ is the Boltzmann constant, $\mathrm{T}$ is the absolute temperature, $\eta$ is the viscosity of the solution $\left(1.35 \times 10^{-3} \mathrm{~N} \mathrm{~s} \mathrm{~m}^{-2}\right.$ for the peptide/TFE solution $\left.{ }^{35}\right), \mathrm{N}_{\mathrm{A}}$ is Avogadro's number, $v_{1}$ and $v_{2}$ are the specific volumes of the solvent molecule (TFE) and the peptide, respectively ${ }^{36}$, and $\delta$ is the fractional amount of TFE bound to the peptide and a value of 0.4 was used under the condition used. The shape factor $(F)$ of 1.0325 was used for a prolate ellipsoid with an axial ratio of 0.55 for the peptide in TFE. ${ }^{34}$

\section{Distance Restraints and Spatial Structure Calculation}

The spatial structure calculation was performed with the program CYANA (version 1.0), ${ }^{21}$ which employs a simulated annealing algorithm in the torsion angle space. Distance restraints of the peptide were obtained from the 2D NOESY spectrum with a mixing time of $200 \mathrm{~ms}$. The NOESY spectrum was analyzed using the Sparky software ${ }^{37}$ through which both NOE intensities and chemical shifts were extracted and served as an input for the program of CYANA. ${ }^{21}$ The final input included the meaningful upper-limit restraints and dihedral angle restraints derived from the GRIDSEARCH. In no case could the stereo-specific assignment be achieved. The 200 randomized starting structures were energy minimized and the 30 CYANA conformers with the lowest target function values were further refined with the AMBER7 program, ${ }^{38,39}$ using the AMBER94 all-atom force-field. ${ }^{40}$

From the calculated structures, 20 best-converged energy-minimized structures were selected to represent the NMR structures. The quality of the final structures was assessed using the PROCHECK- 
NMR program. ${ }^{41}$ Visual analysis of the structures and figure drawings were performed using the MOLMOL program. ${ }^{42}$

\section{RESULTS}

\section{Secondary Structure Estimation by CD Spectroscopy}

CD spectroscopy is a well-established technique for investigating the secondary structure of proteins and peptides. It is particularly useful for monitoring the structural transient of membrane peptides from aqueous media upon insertion into membrane environments. ${ }^{43,44}$ The G185D peptide is highly hydrophobic and insoluble in water and many commonly used organic solvents. We therefore incorporated the peptide into SDS micelles to solublize the peptide and to mimic biological environments. The CD spectra of $20 \mu \mathrm{M}$ G185D peptide solublized in $50 \mathrm{mM}$ SDS micelles at different $\mathrm{pH}$ values are shown in Figure 1. The spectra were characterized by double minima at 208 and $222 \mathrm{~nm}$ and a positive maximum at $194 \mathrm{~nm}$, indicative of a predominant $\alpha$-helical conformation. The CD spectra of the G185D peptide in TFE and DPC micelles were very similar to those in SDS micelles (data not shown). The spectra were deconvoluted using CDPro software, ${ }^{26}$ which has been verified as a reliable approach for analysis of secondary structures of membrane peptides in detergent micelles or phospholipids. ${ }^{19,45}$ The $\alpha$-helical contents were estimated to be ca. $50 \%$ and $41 \%$ at $\mathrm{pH} 4.0$ and 7.4, respectively, similar to both wild-type DMT1-TM4 and G185R peptide under similar conditions. $^{19,20}$ The calculation based on empirical method produced similar results. ${ }^{27,28}$ The conformation of the peptide was dependent on $\mathrm{pH}$ values with a higher helical content observed at a lower $\mathrm{pH}$ value.

\section{NMR Assignments and Secondary Chemical Shifts}


The 2D NMR spectra were well resolved at a wide range of $\mathrm{pH}$ values (4.0 to 7.4). All NMR spectra were assigned according to classical procedures, including spin system identification and sequential assignment. ${ }^{46}$ Initial spin system assignments were obtained using TOCSY spectra and a NOESY spectrum was then used to identify sequential backbone connectivities. The aromatic spin systems of Tyr5, Phe16, Phe18, Phe20 and Tyr24 were verified by the NOE connectivities between aliphatic and aromatic protons. Most of the side chains have been assigned except for a few aromatic side chains (e.g. Phe16, Phe18 and Phe20), where complete assignment was not possible due to spectral overlap. The assignments were made for the G185D peptide in SDS micelles at various $\mathrm{pH}$ values (4.0, 5.5 and 7.5). Figure 2 represents the fingerprint region of the NOESY spectrum of the G185D peptide in SDS micelles at $\mathrm{pH}$ 5.5. The chemical shifts for the backbone protons of the G185D peptide were compared with those for the wild-type (DMT1-TM4) at $\mathrm{pH} 4.0$ and 7.4, as shown in Figure S1. Mutation of Gly7 to Asp7 only caused significant changes in chemical shifts for its nearby residues, such as Tyr5, Gly6, Val8, Leu9, Ile10, Thr11, Ile12 and Ala13, but produced little changes in chemical shifts for both the $\mathrm{N}$ - and C-terminal residues.

The chemical shifts of the $\mathrm{H}^{\alpha}$ protons provide information about secondary structure elements as reported by Wishart and coworkers. ${ }^{47}$ The larger the deviation of the $\mathrm{H}^{\alpha}$ proton chemical shift relative to random coil values, ${ }^{48}$ the more pronounced the secondary structure element should be. A local $\alpha$ helical structure is indicated by upfield shifts relative to random coil values. ${ }^{47}$ The chemical shift deviations relative to random coil values for the $\mathrm{H}^{\alpha}$ of the G185D peptide in SDS micelles at different $\mathrm{pH}$ values were calculated, and are shown in Figure 3. In general, chemical shifts were close to random coil values at higher $\mathrm{pH}$ values except for Leu19 and Tyr24, suggesting that the peptide becomes less structured at such $\mathrm{pH}$ values. The changes of $\mathrm{pH}$ values induced dramatic changes in $\mathrm{H}^{\alpha}$ chemical shifts for the C-terminal residues, in particular for Phe20 and Leu21, indicating that the folding of the 
C-terminus is highly $\mathrm{pH}$ dependent. As illustrated in Figure 3, the peptide adopts predominantly $\alpha$ helical conformations, consistent with NOE patterns (vide infra).

Several medium range NOEs, i.e. $d_{\alpha N}(i, i+3), d_{\alpha \beta}(i, i+3)$ and $d_{\alpha N}(i, i+4)$, and strong sequential NOEs between amide protons also supported a helical structured peptide in the middle portion (Figure 4). More medium-range NOEs were found at the C-terminus at $\mathrm{pH} 4.0$, indicative of a more helical structure at a lower $\mathrm{pH}$ value and consistent with our $\mathrm{CD}$ experiments. There was a lack of medium range NOEs in the $\mathrm{N}$-terminus at all $\mathrm{pH}$ values studied, which implies that the $\mathrm{N}$-terminus is in an extended conformation.

\section{Spatial Structures of G185D Peptide in SDS Micelles}

The three-dimensional structures of the G185D peptide in SDS micelles were obtained based on a total of 287 (pH 4.0), $345(\mathrm{pH} 5.5)$ and 345 (pH 7.4) NOE assignments, 197, 246 and 240 non-redundant distance restraints (Table I). A set of 200 structures of the peptide in SDS micelles at each pH value was calculated. The 30 structures with the lowest target function values were selected with no distance violations greater than $0.2 \AA$, and no angle constraint violations greater than $5^{\circ}$. The final 20 bestconverged energy-minimized conformers were selected at each $\mathrm{pH}$ value to represent its structures in micelles. Statistics from PROCHECK-NMR ${ }^{41}$ show that in the well-defined region in each $\mathrm{pH}$ value, over $90 \%$ of the backbone dihedral angles occupied the most favored regions of the Ramachandran space, and none were found in the disallowed region (Table I). The pair-wise root mean square deviations (RMSDs) between the 20 best-converged energy-minimized structures and mean structures were also analyzed at different regions (Table I). The results showed that the structures were welldefined at each helical segment at different $\mathrm{pH}$ values.

Figure 5A shows superimpositions of the backbone atoms (Leu9-Phe18) of the final 20 bestconverged energy-minimized structures in SDS micelles at $\mathrm{pH} 4.0,5.5$ and 7.4. The overall structures 
were characterized by a well-defined helical region flanked by disordered $\mathrm{N}$ and C-termini. The Nterminus from Arg1 to Gly6 was flexible and disordered at all $\mathrm{pH}$ values studied, while the C-terminus became well-folded only at low $\mathrm{pH}$ values, as evidenced by the presence of $d_{\alpha N}(i, i+3)$ and $d_{\alpha N}(i, i+4)$ interactions between residues 20-24 at a such $\mathrm{pH}$ (4.0). The length of helix was dependent on $\mathrm{pH}$ values (e.g. Leu9 to Asp22 at $\mathrm{pH} 4.0$ versus Val8 to Phe18 at $\mathrm{pH} 7.4$ ). The C-terminus was bent towards the helical axis at higher $\mathrm{pH}$ values. The peptide exhibited a similar structure at $\mathrm{pH} 5.5$ to that at $\mathrm{pH}$ 7.4. The side chains of the peptide at $\mathrm{pH} 5.5$ are shown in Figure 5B. It can be seen clearly that the peptide has an amphipathic characteristic with the hydrophilic residues Asp7, Thr11, Asp14 and Thr15 lying in one side of the helix, while the opposite side of the helix is occupied by hydrophobic residues. The residue Pro3 adopted a trans conformation, evidenced by the presence of strong NOE between the $\mathrm{H}^{\alpha}$ of $\mathrm{Val} 2$ and $\mathrm{H}^{\delta}$ of Pro3. The results from the tertiary structure calculation agree relatively well with the suggestions based on NOE patterns and secondary chemical shift analysis. The H-bonds of $\mathrm{H}_{i+4}^{\mathrm{N}} \rightarrow \mathrm{CO}_{\mathrm{i}}$, which are characteristic for $\alpha$-helices, were found in the well-defined regions for the majority conformers of the G185D peptide at various $\mathrm{pH}$ values, indicating that the H-bonding plays an important role in stabilizing the structure of the peptide.

Electrostatic potential maps for the contact surface of the calculated structures for the G185D peptide in SDS at both $\mathrm{pH} 4.0$ and 7.4 were computed using the MOLMOL program. The charge distribution showed amphipathic characteristics. Negative charged Asp7, Asp14 and Asp22 lay in one side of the helix, while the opposite side of the helical-core region was quite hydrophobic, although with positive charged Arg1 and Lys23 flanking at both ends (Figure 6). The negatively charged surface of the peptide was not parallel to the helical axis at $\mathrm{pH} \mathrm{7.4,} \mathrm{but} \mathrm{twisted} \mathrm{along} \mathrm{the} \mathrm{helix} \mathrm{and} \mathrm{bent} \mathrm{at} \mathrm{the}$ C-terminus, consistent with calculated structures. These amphipathic properties might provide a basis for the peptide self-assembly to form channel architectures. 


\section{Amide Proton Exchange Experiments}

One-dimensional ${ }^{1} \mathrm{H}$ NMR spectra were recorded at different time intervals after the addition of $\mathrm{D}_{2} \mathrm{O}$ in the lyophilized peptide sample containing $300 \mathrm{mM} \mathrm{SDS}-d_{25}$ at $\mathrm{pH}^{*}$ 5.3. The 2D NOESY spectra were then recorded after no obvious changes occurred in the $1 \mathrm{D}$ spectrum (ca. $150 \mathrm{~min}$ ). It was noticed that the amide protons of both the $\mathrm{N}$ - and $\mathrm{C}$-terminal residues exchanged rapidly and disappeared after ca. $60 \mathrm{~min}$, while those residues involved in the formation of helix exchanged slowly (data not shown). However, Asp14 exchanged relatively quickly and disappeared within 2 hrs after the addition of $\mathrm{D}_{2} \mathrm{O}$. After 22.5 hrs, only Ile10, Ile12, Ala13, Phe16, Val17 and Phe20 were still observable in the NOESY spectrum (data not shown). All the amide protons disappeared from 1D spectrum after 48 hrs. This experiment demonstrated that the H-bonding played an important role in the stabilization of the peptide. Rapid exchange of amide protons of polar residues indicated there is a solvent accessibility in the structure.

\section{Membrane Location}

\section{Effect of 16-Doxyl-Stearic Acid Spin Label on the ${ }^{1}$ H NMR Signals}

Paramagnetic spin label was used to probe the positioning of the peptide relative to the surface and interior of the micelle. The relaxation agent, 16-doxyl-stearic acid, contains doxyl headgroups, a cyclic nitroxide with unpaired electrons attached to the aliphatic chain carbon in the position of 16 . Previous studies have demonstrated that the doxyl group of the relaxation agent 16-doxyl-stearic acid is located close to the center of the micelle. ${ }^{49}$

Specific broadening or even missing of the proton signals in the G185D peptide in SDS micelles was monitored by using NOESY (or TOCSY) spectra at a SDS/spin label molar ratio of 60:1, i.e. approximately one spin label per micelle. The addition of 16-doxyl-stearic acid into the peptide/SDS micelle solution at $\mathrm{pH} 5.5$ resulted in a significant broadening of the $\mathrm{H}^{\alpha}-\mathrm{H}^{\mathrm{N}}$ cross-peaks of Ala13, and 
a moderate broadening of the cross-peaks of residues situated in both the helical core region and the Nterminal region (Figure 7). This indicated that residues of both the N-termini and helical core are embedded in the micelles. However, no broadening was found for the C-terminal residues (Phe20Tyr24) in the presence of 16-doxyl-stearic acid (Figure 7), suggesting that the C-terminal residues may be exposed outside the SDS micelles in the aqueous phase. Similar changes occurred at pH 4.0 upon addition of 16-doxyl-stearic acid (data not shown), implying no significant alternation in the location of the peptide relative to SDS micelle surface.

\section{Effect of Paramagnetic Metal Ions on ${ }^{1}$ H NMR Signals}

Paramagnetic metal ion broadening is an alternative approach, which can be employed to probe the location of the peptide relative to the micelles. In this work, it can be used to probe the likely formation of a solvent- or metal-accessible channel or pore. Addition of $\mathrm{Mn}^{2+}(0.2 \mathrm{mM})$ to the G185D peptide in SDS micelles at $\mathrm{pH} 5.5$ led to the complete disappearance of the $\mathrm{H}^{\alpha}-\mathrm{H}^{\mathrm{N}}$ cross-peaks of the C-terminal residues (Leu19-Tyr24) (Figure 7), which suggests that these residues are likely located outside SDS micelles. A 3-4 periodic (Asp7, Thr11 and Asp14) broadening of the $\mathrm{H}^{\alpha}-\mathrm{H}^{\mathrm{N}}$ cross-peaks from Asp7 to Leu19 was also noticed (Figure 7), indicative of a solvent-accessibility. However, less broadening was observed for the N-terminal residues (Val2-Gly6) in the presence of paramagnetic metal ions (Figure 7). Further increases in $\mathrm{Mn}^{2+}$ concentration produced only a trivial effect on the remaining peaks (data not shown). This may suggest that the N-terminus of the peptide is embedded in the SDS micelles, while the C-terminus may be more solvent-exposed. Similar effects were also observed when using a larger paramagnetic cation of $\mathrm{Gd}^{3+}$ (data not shown). Unexpectedly, when the $\mathrm{pH}$ value of the solution was lowered in the presence of $\mathrm{Mn}^{2+}$ from 5.5 to 4.0 , the intensities of the $\mathrm{H}^{\alpha}-\mathrm{H}^{\mathrm{N}}$ cross-peaks of majority residues (in particular Asp7, Thr11, Asp14, Phe18, Leu19 and Phe20) were almost unaffected by the presence of $\mathrm{Mn}^{2+}$. In addition, the C-terminal residues (e.g. Leu21, Asp22, Lys23 and Tyr24) 
also reappeared and gained nearly $40 \%$ of their intensities compared to those in the absence of $\mathrm{Mn}^{2+}$ (Figure 7). This implicates that the C-terminus is also inserted into the SDS micelles at a low $\mathrm{pH}$.

\section{Association of the peptide in TFE}

Diffusion measurements have been widely used to monitor self-association phenomena in proteins and peptides. ${ }^{34,50}$ In order to investigate the possible self-association of the peptide, the diffusion coefficient was measured by diffusion ordered spectroscopy (DOSY). The DOSY spectrum shows almost a single diffusion coefficient at $25^{\circ} \mathrm{C}$ with the diffusion coefficient (D) of $1.029 \times 10^{-10} \mathrm{~m}^{2} \mathrm{~s}^{-1}$ (Figure S2). If a prolate ellipsoid model was assumed for the peptide in TFE, ${ }^{34}$ the molecular mass for the G185D peptide is $8.4 \mathrm{kDa}$, corresponding to the molecular mass of a trimer of the peptide (molecular mass of the peptide $2.82 \mathrm{kDa}$ ).

\section{DISCUSSION}

DMT1 plays an important role in maintaining intracellular iron homeostasis. However, the mechanism through which iron was transported remains to be elucidated. The fourth transmembrane domain has been demonstrated to be crucial for the biological function of its integral protein. ${ }^{2,5}$ Characterization of the three-dimensional structure of DMT1 would be a great help in understanding its function. Unfortunately, it is difficult to determine the structure for large membrane proteins in the short term using either X-ray crystallography or NMR spectroscopy. The model peptides, corresponding to the sequences of potential functional segments or domain of integral proteins, were therefore used as an alternative approach to reveal the structure and topology of their relative integral proteins, with the ultimate goal of establishing the 3D structure of integral proteins. ${ }^{12,13,16,51}$ Indeed, 3D structural models of lactose permease with 12-transmembrane domains have been derived without using crystals recently, based on its transmembrane topology, secondary structure, and numerous interhelical contacts. $^{52}$ 
The two glycine residues located within the putative transmembrane domain 4 of Nramp proteins appeared to be important for the function of its integral protein, since both disease-causing mutations in Nramp family proteins occurred at these two glycine residues. ${ }^{2,9}$ Large proportions of glycine residues are often noticed in the putative TM domains of integral membrane proteins. It appears that glycine located within multi-spanning membrane proteins does not impart characteristics of flexibility normally associated with this residue, but instead plays an important role in providing a small sidechain for packing interaction. ${ }^{53,54} \mathrm{We}$ have previously characterized the structures of a peptide, corresponding to the wild-type of the fourth transmembrane domain of DMT1, in membrane-like environments by using molecular dynamic and simulated annealing approach. ${ }^{19,20}$ In the present study, we aimed to investigate the effect of a substitution of the Gly185 (Gly7 in the peptide) by a negatively charged residue Asp on the structures, orientation and aggregation behavior of the peptide in SDS micelles.

The spatial structures of the G185D peptide in SDS micelles at various $\mathrm{pH}$ values have been determined by molecular dynamics calculations. The peptide assumes $\alpha$-helical conformations with no kink from Leu9 to Leu19 at pH 5.5 and is well-defined by NMR data, evidenced by the small target functions and RMSD values (Table I). The N-terminus (Arg1 to Gly6) is poorly defined and appeared to be in a random structure at all $\mathrm{pH}$ values. The folding of the $\mathrm{C}$-terminus is highly $\mathrm{pH}$-dependent. It is less structured and bent towards the axis of the helical core at higher $\mathrm{pH}$ values (5.5 and 7.4), whereas it becomes well-folded at a lower $\mathrm{pH}$ value (4.0) and the helix extends to Asp22. The structural characteristics of the G185D peptide are extremely similar to the wild-type peptide, although the helical length and spanning region are slightly different for each peptide. Glycine is well-known as an intrinsically flexible residue, which is capable of adopting most of the dihedral angles available in a Ramachandran plot. ${ }^{55}$ However, it is frequently identified as a helix-breaker in globular proteins and water-soluble peptides. The substitution of the Gly7 by either a large positively charged Lys ${ }^{20}$ or a small negatively charged Asp does not significantly alter the spatial structures of the fourth transmembrane peptides in membrane-like SDS micelles. 
The location of the G185D peptide was investigated by paramagnetic broadening of 16-doxyl-stearic acid spin label and $\mathrm{Mn}^{2+}$ on peptide NMR signals. Paramagnetic spin labels are known to be efficient relaxation agents, which selectively broaden resonances in their vicinity $\left(\propto \mathrm{r}^{-6}\right.$, where $\mathrm{r}$ is the distance between the paramagnetic centre and the nuclear spin). ${ }^{11}$ As illustrated in Figure 7, the peptide is embedded into the interior of the SDS micelles with the C-terminus surface exposed at $\mathrm{pH} 5.5$. When the $\mathrm{pH}$ value is lowered from 5.5 to 4.0 , the G185D peptide is likely entirely buried inside the micelles, as judged from little effect of $\mathrm{Mn}^{2+}$ on NOESY cross-peaks at this $\mathrm{pH}$ value. $\mathrm{Mn}^{2+}$ has been previously demonstrated as a paramagnetic probe to explore solvent-exposed residues for membrane peptides, since it does not enter the membrane and should only broaden the residues situated in aqueous phase or at the surface of detergent micelles. ${ }^{11}$ We have shown that the G185D peptide is embedded into the SDS micelles interior, and simultaneously noticed that $\mathrm{Mn}^{2+}$ caused significant broadening of the cross-peaks of hydrophilic residues Asp7, Thr11 and Asp14. The self-association of the peptide into a trimer in TFE as shown by the diffusion study suggests that the peptide may assume a channel in SDS micelles via similar association. Rapid exchange of amide protons in both $\mathrm{N}$ - and C-termini also supported the idea of formation of a pore or channel since the N-terminus is embedded in SDS micelles while the $\mathrm{C}$-terminus resides outside of micelles at $\mathrm{pH}$ 5.5. It is noteworthy that a certain proportion of hydrophilic and even charged residues is often incorporated into the TM domains. These residues are important determinants of tertiary structure in multi-spanning membrane proteins. ${ }^{56,57}$ Moreover, they are also likely to be involved in the transport process of transport proteins ${ }^{58}$ and in the formation of aqueous pores in prions and other channel proteins. ${ }^{58,59}$ Both the side-chain and the charge distribution of the G185D peptide exhibit amphipathic characteristics (Figure 6), which support the idea of formation of a channel or pore. Unfortunately, we could not identify any NOEs belonging to intramolecular interactions, probably due to highly symmetrical assemblies. Unlike the G185R peptide, which displays a lower intensity and a poor signal-to-noise ratio at higher concentrations, the G185D peptide displayed similar intensities and signal-to-noise ratios in both 1D and 2D NMR spectra as the wild-type peptide. Our diffusion study has shown that the diffusion coefficient of the G185D peptide is almost the same as the wild-type peptide in TFE. ${ }^{20}$ This suggests that the G185D peptide 
may exhibit similar aggregation behavior (trimer) as the wild-type peptide in SDS micelles. The significant broadening effects of $\mathrm{Mn}^{2+}$ may be either due to permeation or exchange of $\mathrm{Mn}^{2+}$ bound water with the water and amide protons in the channel. At a low $\mathrm{pH}$ value (4.0), the weaker effect of $\mathrm{Mn}^{2+}$ on peptide NMR signals is probably due to the movement of the C-termini towards the interior of the micelles, thereby "blocking" the $\mathrm{Mn}^{2+}$ entrance. In contrast to both the wild-type and G185R peptides, neither Gly7 nor Arg7 were situated within the pore or channel, as evidenced by the weaker broadening effect from $\mathrm{Mn}^{2+} \cdot{ }^{20}$ However, the Asp7 of the G185D peptide also dramatically broadened in the presence of $\mathrm{Mn}^{2+}$ at $\mathrm{pH} 5.5$ (Figure 7). The Asp7 of the G185D peptide is close to and even included in the helical conformation in some of the calculated structures. Therefore it is reasonable to assume that it also participates in the formation of the channel.

\section{CONCLUSIONS}

Both CD and NMR spectroscopies showed that the G185D peptide, corresponding to the fourth transmembrane domain of DMT1 with G185D mutation, exhibits predominately $\alpha$-helical structures in membrane-mimetic environments (SDS micelles). The three dimensional structure of the peptide was obtained by molecular dynamics calculation, using a simulated annealing approach. The middle segment of the peptide forms a well-defined helical conformation, while the $\mathrm{N}$-terminus is highly flexible and poorly defined. Interestingly, the folding of the $\mathrm{C}$-terminus is triggered by $\mathrm{pH}$ values, and it forms a helical structure only at a low $\mathrm{pH}$ (4.0). The peptide is embedded in the SDS micelles with the C-terminus surface exposed at $\mathrm{pH} 5.5$ or 7.4, but shrunk into the micelles at $\mathrm{pH} 4.0$. It is likely to self-assemble to assume a water-filled channel (probably a trimer) through which metal ions may pass. The mutation of the Gly7 to a negatively charged and less bulky aspartate does not significantly alter the structure, orientation and aggregation behavior compared with the wild-type peptide. Although structural characterization of model peptides may not represent the active structure of the fourth TM domain of DMT1 in biological membranes, it may provide insights into the adaptability of channelforming of integral DMT1 either by self-association or by arrangement of its multi-spanning TM 
domains, and substitution of the Gly7 by an aspartate is unlikely to abolish its properties of channelforming and metal permeation.

We would like to thank the University of Hong Kong (URC to H.Z.S. and Q.Y.H.), Hong Kong Research Grants Council (HKU 7227/02M to Q.Y.H.) and the Area of Excellence Scheme of the University Grants Committee (Hong Kong) for financial support. The 600-MHz NMR spectrometer was purchased through an equipment grant (large item of equipment) from the University of Hong Kong. 
Table I NMR Restraints and Statistics for the Ensemble of 20 Structures Calculated for the G185D Peptide in SDS Micelles at Different pH Values

\begin{tabular}{|c|c|c|c|}
\hline Property & $\mathrm{pH} 4.0$ & pH 5.5 & $\mathrm{pH} 7.4$ \\
\hline Average target functions $\AA^{2}$ & $0.071 \pm 0.025$ & $0.23 \pm 0.032$ & $0.22 \pm 0.028$ \\
\hline Number of nonredundant distance restraints & 197 & 246 & 240 \\
\hline Intraresidual & 92 & 117 & 111 \\
\hline Sequential & 66 & 90 & 87 \\
\hline Medium range & 39 & 39 & 40 \\
\hline Long range & 0 & 0 & 0 \\
\hline Average sum of distance restraint violations & $0.50 \pm 0.20$ & $1.70 \pm 0.20$ & $1.60 \pm 0.20$ \\
\hline Average maximum distance restraints violation & $0.14 \pm 0.04$ & $0.20 \pm 0.03$ & $0.18 \pm 0.02$ \\
\hline AMBER energy $\left(\mathrm{Kcal} \mathrm{mol}^{-1}\right)$ & $-885.5 \pm 50.6$ & $-887.0 \pm 36.0$ & $-872.5 \pm 38.1$ \\
\hline \multicolumn{4}{|l|}{ R.m.s. deviation from the mean structure $(\AA)$} \\
\hline \multicolumn{4}{|l|}{ Residues 1-24 } \\
\hline Backbone heavy atoms & $2.75 \pm 0.87$ & $3.34 \pm 1.05$ & $3.53 \pm 0.93$ \\
\hline All heavy atoms & $4.25 \pm 0.92$ & $4.30 \pm 0.95$ & $4.91 \pm 1.20$ \\
\hline Residues for helical span & Leu9-Asp22 & Va19- Leu19 & Val8-Phe18 \\
\hline Backbone heavy atoms & $0.46 \pm 0.16$ & $0.24 \pm 0.09$ & $0.34 \pm 0.12$ \\
\hline All heavy atoms & $1.34 \pm 0.26$ & $0.92 \pm 0.17$ & $0.96 \pm 0.21$ \\
\hline \multicolumn{4}{|l|}{ Ramachandran plot statistics } \\
\hline \multicolumn{4}{|l|}{ (at each helical span) } \\
\hline Residues in most favored region (\%) & 93.7 & 93.2 & 97.7 \\
\hline Residues in additionally allowed region (\%) & 6.3 & 6.8 & 2.3 \\
\hline Residues in generously allowed region (\%) & 0 & 0 & 0 \\
\hline Residues in disallowed region (\%) & 0 & 0 & 0 \\
\hline
\end{tabular}




\section{REFERENCES}

1. Gunshin, H.; Mackenzie, B.; Berher, U.V.; Gunshin, Y.; Romero, M. F.; Boron, W. F.; Nussberger, S.; Gollan, J. L.; Hediger, M.A. Nature 1997, 388, 482-488.

2. Fleming, M. D.; Trenor III, C. C.; Su, M. A.; Foernzler, D.; Beier, D. R.; Dietrich, W. F.; Andrews, N. C. Nat Genet 1997, 16, 383-386.

3. Canonne-Hergaux, F.; Gruenheid, S.; Ponka, P.; Gros, P. Blood 1999, 93, 4406-4417.

4. Tabuchi, M.; Yoshimori, T.; Yamaguchi, K.; Yoshida, T.; Kishi, F. J Biol Chem 2000, 275, 22220 22228.

5. Su, M. A.; Trenor, C. C.; Fleming, J. C.; Fleming, M. D.; Andrews, N. C. Blood 1998, 92, $2157-$ 2163.

6. Picard, V.; Govoni, G.; Jabado, N.; Gros, P. J Biol Chem 2000, 275, 35738-35745.

7. Tandy, S.; Williams, M.; Leggett, A. et al. J Biol Chem 2000, 275, 1023-1029.

8. Fleming, M. D.; Romano, M. A.; Su, M. A.; Garrick, L. M.; Garrick, M. D.; Andrews, N. C. Proc Natl Acad Sci USA 1998, 95, 1148-1153.

9. Vidal, S. M.; Malo, D.; Vogan, K.; Skamene, E.; Gros, P. Cell 1993, 73, 469-485.

10. Opella, S. J.; McDonnell, P. A. In NMR of Proteins. Clore G. M. and Gronenborn, A. M. editors. CRC/Boca Raton. 159-189, 1993.

11. Damberg, P.; Jarvet, J.; Gräslund, A. Methods Enzymol 2001, 339, 271-285.

12. Opella, S. J.; Marassi, F. M.; Gesell J. J.; Valente, A. P.; Kim, Y.; Oblatt-Montal, M.; Montal, M. Nat Struct Biol 1999, 6, 374-379.

13. MacKenzie, K. R.; Prestegard, J. H.; Engelman, D. M. Science 1997, 276, 131-133.

14. Arshava, B.; Taran, I.; Xie, H.; Becker, J. M.; Naider, F. Biopolymers 2002, 64, 161-176.

15. Rozek, A.; Friedrich, C. L.; Hancock, R. E. W. Biochemistry 2000, 39, 15765-15774.

16. Hunt, J. F.; Earnest, T. N.; Bousche, O.; Kalghatgi, K.; Reilly, K.; Horvath, C.; Rothschild, K. J.; Engelman, D. M. Biochemistry 1997, 36, 15156-15176.

17. Valentine, K. G.; Liu, S. F.; Marassi, F. M.; Veglia, G.; Opella, S. J.; Ding, F. X.; Wang, S. H.; Arshava, B.; Becker, J. M.; Naider, F. Biopolymers 2001, 59, 243-256.

18. Arshava, B.; Liu, S. F.; Jiang, H.; Breslav, M.; Becker, J. F.; Nadier, F. Biopolymers 1998, 46, 343-357.

19. a) Li, H. Y.; Li, F.; Sun, H. Z.; Qian, Z. M. Biochem J 2003, 372, 757-766.

b) Li, H. Y.; Li, F.; Qian, Z. M.; Sun, H. Z. Eur J Biochem 2004, 271, 1938-1951.

20. Li, F.; Li, H.Y.; Chen, G.H.; He, Q.Y.; Sun, H. Z. submitted for publication 
21. Güntert, P.; Mumenthaler, C.; Wüthrich, K. J Mol Biol 1997, 273, 283-298.

22. Braunschweiler, L.; Ernst, R. R. J Magn Reson 1983, 53, 521-528.

23. Bax, A.; Davis, D. G. J Magn Reson 1985, 65, 355-360.

24. Macura, S.; Ernst, R. R. Mol Phys 1980, 41, 95-117.

25. Kumar, A.; Ernst, R. R.; Wüthrich, K. Biochim Biophys Res Commun 1980, 95, 1-6.

26. Sreerama, N.; Woody, R. W. Anal Biochem 2000, 287, 252-260.

27. Greenfield, N.; Fasman, G. D. Biochemistry 1969, 8, 4108-4116.

28. Ben-Efraim, I.; Shai, Y. Biophys J 1997, 72, 85-96.

29. Marion, D.; Wuthrich, K. Biochem Biophys Res Commun 1983, 113, 967-974.

30. Griesinger, C.; Otting, G.; Wüthrich, K. J Am Chem Soc 1988, 110, 7870-7872.

31. Piotto, M.; Prosser, R. S.; Sklenar, V. J Biomol NMR 1992, 2, 661-665.

32. Sklenar, V.; Piotto, M.; Leppik, R.; Saudek, V. J Magn Reson Ser A 1993, 102, 241-245.

33. Mills, R. J. Phys. Chem. 1973, 77, 685-688.

34. Yao, S; Howlett, G. J.; Norton, R. S. J. Biomol. NMR 2000, 16, 109-119.

35. Fioroni, M.; Diaz, M. D.; Burger, K.; Berger, S. J. Am. Chem. Soc. 2002, 124, 7737-7744.

36. Perkins, S.J. Eur. J. Biochem. 1986, 157, 169-180.

37. Goddard, T. D.; Kneller, D.G. SPARKY 3, University of California, San Francisco.

38. Pearlman, D. A.; Case, D. A.; Caldwell, J. W.; Ross, W. S.; Cheatham, T. E.; DeBolt, S.; Ferguson, D.; Seibel, G.; Kollman, P. Comut Phys Commun 1995, 9, 11-41.

39. Case, D. A.; Pearlman, D. A.; Caldwell, J. W.; Cheatham III, T. E.; Wang, J.; Ross, W. S.;

Simmerling, C. L.; Darden, T. A.; Merz, K. M.; Stanton, R. V.; Cheung, A. I.; Vincent, J. J.;

Crowley, M.; Tsui, V.; Gohike, H.; Radmer, R. J.; Duan, Y.; Pitera, J.; Massova, I.; Seibel, G. L.;

Singh, U. C.; Weiner, P. K.; Kollman. P. A. AMBER 7. University of California, San Francisco, 2002.

40. Cornell, W. D.; Cieplak, P.; Bayly, C. I.; Gould, I. R.; Merz, K. M.; Jr. Ferguson, D. M.;

Spellmeyer, D. C.; Fox, T.; Caldwell, J. W.; Kollman, P. A. J Am Chem Soc 1995, 117, 5179-5197.

41. Laskowski, R. A.; Rullmannn, J. A.; MacArthur, M. W.; Kaptein, R.; Thornton, J. M. J Biomol

NMR 1996, 8, 477-486.

42. Koradi, R.; Billeter, M., Wüthrich, K. J Mol Graph 1996, 14, 51-55.

43. Ladokhin, A. S.; Selsted, M. E.; White, S. H. Biochemistry 1999, 38, 12313-12319.

44. Aivazian, D.; Stern, L. J. Nat Struct Biol 2000, 7, 1023-2026. 
45. Watson, R. M.; Woody, R. W.; Lewis, R. V.; Bohle, D. S.; Andreotti, A. H.; Ray, B.; Miller, K. W. Biochemistry 2001, 40, 14037-14046.

46. Wüthrich, K. NMR of Proteins and Nucleic Acids. John Wiley, New York. 1986.

47. Wishart, D. S.; Skyes, B. D.; Richards, F. M. Biochemistry 1992, 31, 1647-1651.

48. Wishart, D. S.; Sykes, B. D. Methods Enzymol 1994, 239, 363-392.

49. Papavoine, C. H.; Konings, R. N.; Hilbers, C. W.; van de Ven, F. J. Biochemistry 1994, 33, 1299012997.

50. Danielsson, J.; Jarvet, J.; Damberg, P.; Gräslund, A. Magn. Reson. Chem. 2002, 40, S89-S97.

51. Tang, P.; Mandal, P. K.; Xu, Y. Biophys J 2002, 83, 252-262.

52. Sorgen, P. L.; Hu, Y.; Guan, L., Kaback, H. R.; Girvin, M. E. Proc Natl Acad Sci USA 2002, 9, 14037-14040.

53. Jung, K.; Jung, H.; Colacuricio, P.; Kaback, H. R. Biochemistry 1995, 269, 1030-1039.

54. Loo, T. W. J Biol Chem 1994, 269, 7243-7248.

55. Richardson, J. S.; Richardson, D. C. Prediction of Protein Structure and the Principles of Protein Conformation. Plenum Press, New York, 1989.

56. Deisenhofer, J.; Epp, O.; Miki, K.; Huber, R.; Michel, H. Nature 1985, 318, 618-624.

57. Jennings, M. L. Annu Rev Biochem 1989, 58, 999-1027.

58. Deber, C. M.; Brandle, C. J.; Deber, R. B.; Hsu, L. C.; Young, X. K. Arch Biochem Biophys 1986, $251,68-76$.

59. Popot, J. L.; Engelman, D. M. J Mol Biol 1990, 198, 655-676. 


\section{Figure captions:}

FIGURE 1 CD spectra of the G185D peptide in SDS micelles at pH 4.0 (solid line) and 7.4 (broken line). The fraction of $\alpha$-helical conformation was estimated to be ca. $50 \%$ and $41 \%$ at $\mathrm{pH} 4.0$ and 7.4 , respectively.

FIGURE 2 The fingerprint region of the 600-MHz NOESY spectra of $2 \mathrm{mM}$ G185D peptide in 300 mM SDS- $d_{25}$ micelles at pH 5.5, $298 \mathrm{~K}$, mixing time of $200 \mathrm{~ms}$. The sequential assignment is also indicated.

FIGURE 3 Chemical shift deviations of $\mathrm{H}^{\alpha}$ of the G185D peptide in SDS micelles at different $\mathrm{pH}$ values relative to random coil values in water.

FIGURE 4 Summary of NOE connectivities for the G185D peptide in SDS micelles at pH 4.0 (top); 5.5 (middle) and 7.4 (bottom).

FIGURE 5 Panel A: Superpositions of the backbone atoms for the final 20 best-converged energyminimized structures of the G185D peptide in SDS micelles at $\mathrm{pH} 4.0$ (red), with those at $\mathrm{pH} 5.5$ (green) and $\mathrm{pH} 7.4$ (blue). The structures were aligned for the best fit of the backbone of residues Leu9-Leu19. Panel B: Mean structure of G185D peptide in SDS micelles at pH 4.0. The side chains are displayed with the hydrophilic residues colored in red for negatively charged (Asp) or neutral residues (Thr), and in blue for positively charged residues (Arg and Lys). 
FIGURE 6 Surface plots of the minimized average structures of the G185D peptide in SDS micelles at pH 4.0 and 7.4. The hydrophobic surfaces are colored in light gray, while the polar surfaces are shown in red (negative) and blue (positive).

FIGURE 7 Residual relative intensities of $\mathrm{H}^{\alpha}-\mathrm{H}^{\mathrm{N}}$ NOESY cross-peaks of the G185D peptide in SDS micelles in the presence of 16-doxyl-stearic acid $(5 \mathrm{mM})$ at $\mathrm{pH} 5.5(\mathbf{\Delta}) ; \mathrm{Mn}^{2+}(0.2 \mathrm{mM})$ at $\mathrm{pH} 5.5(\mathrm{O})$ and $\mathrm{Mn}^{2+}(0.2 \mathrm{mM})$ at $\mathrm{pH} 4.0(\mathbf{O})$. 
FIGURE 1

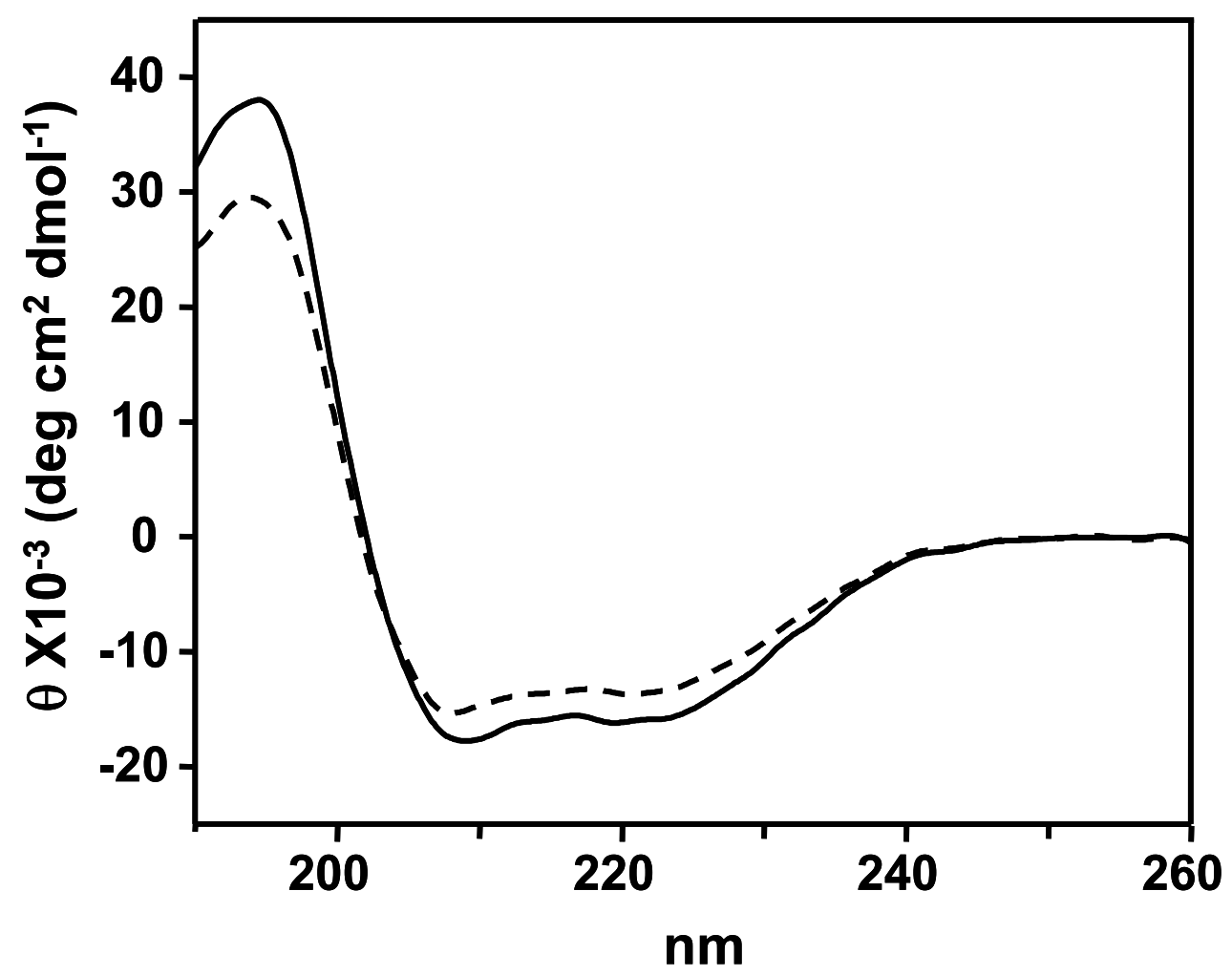


FIGURE 2

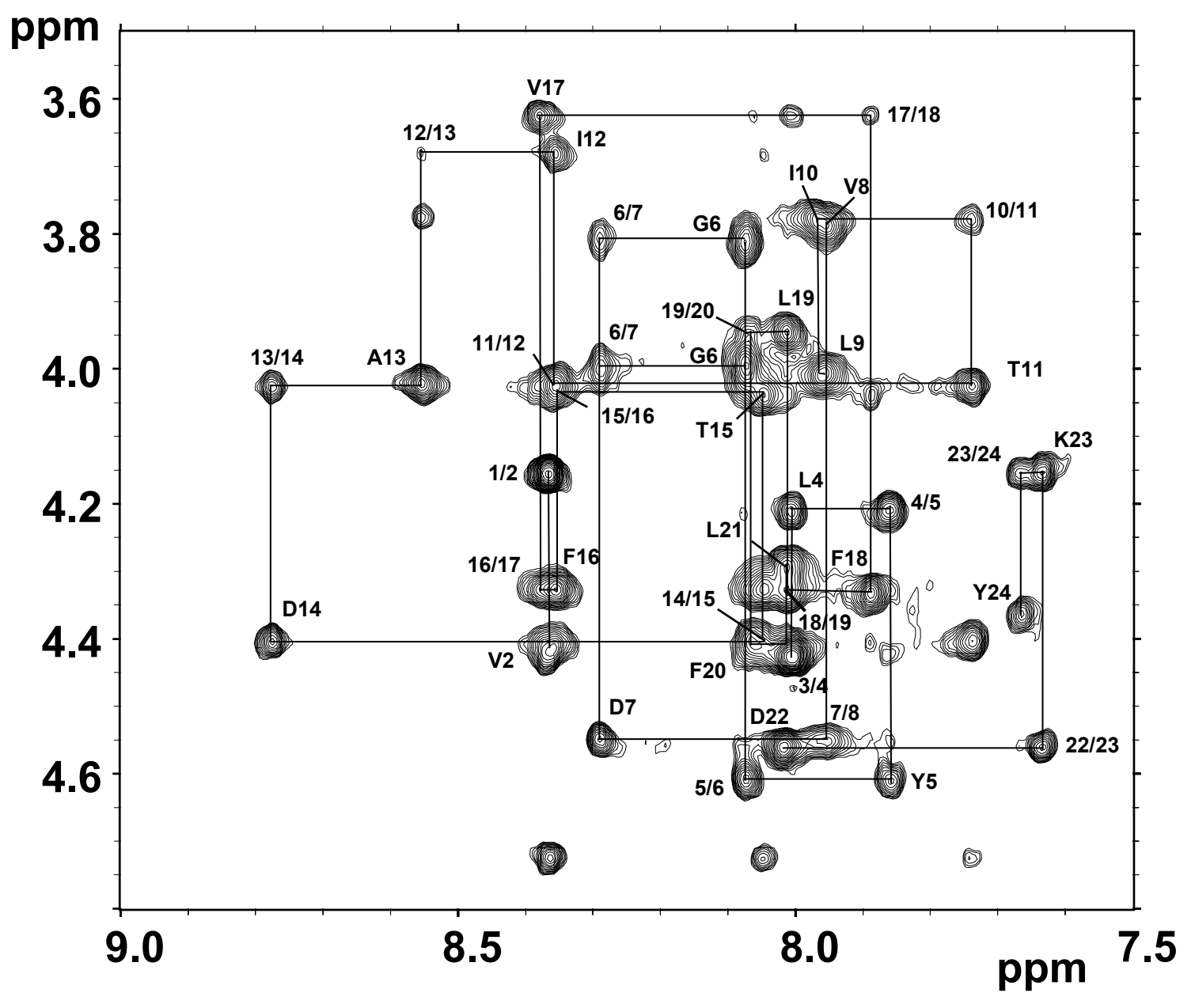


FIGURE 3

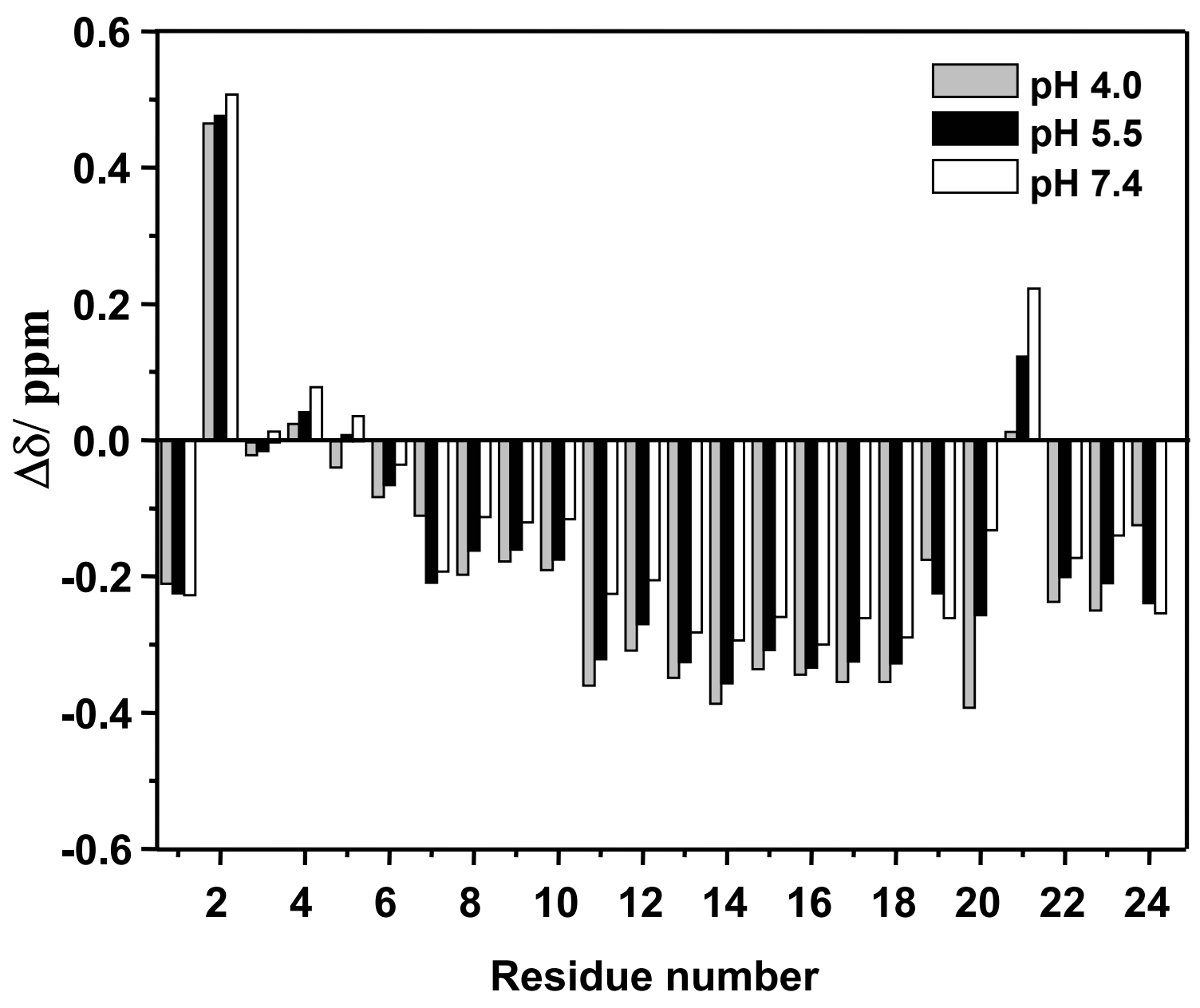


FIGURE 4

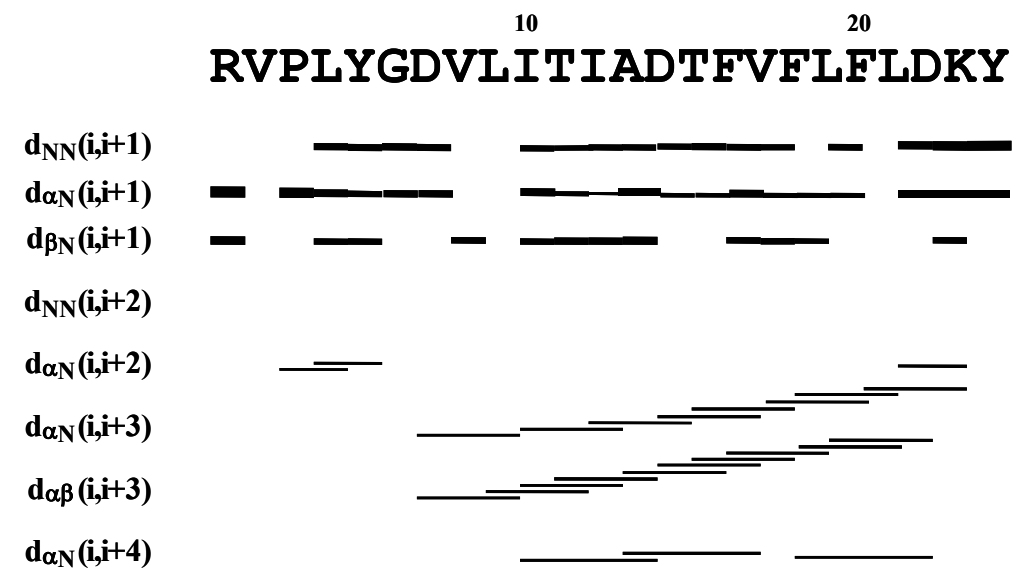

\section{RVPLYGDVIITIADTEVFLFLDKY}

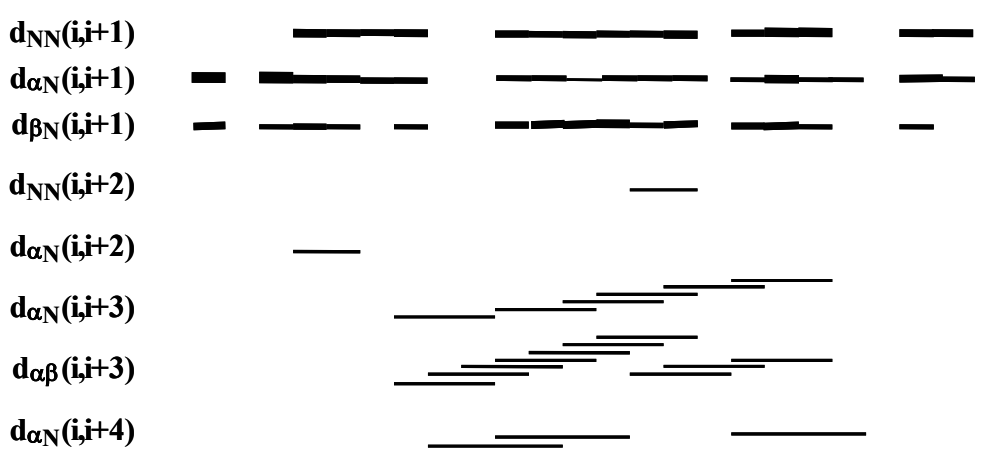

1020

RVPLYGDVLITIADTFVELFLDKY

$\mathbf{d}_{\mathrm{NN}}(\mathbf{i}, \mathbf{i}+\mathbf{1})$

$d_{\alpha N}(i, i+1)$

$d_{\beta N}(i, i+1)$

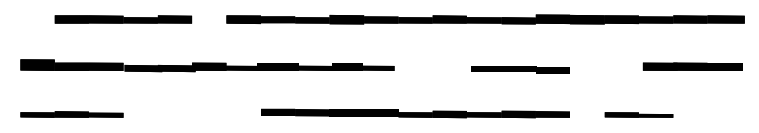

$d_{\mathrm{NN}}(\mathbf{i}, \mathbf{i}+\mathbf{2})$

$d_{\alpha N}(i, i+2)$

$d_{\alpha N}(i, i+3)$

$\mathbf{d}_{\alpha \beta}(\mathbf{i}, \mathbf{i}+\mathbf{3})$

$d_{\alpha N}(i, i+4)$

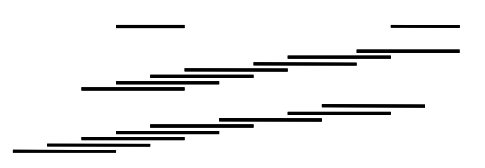




\section{FIGURE 5}

(A)

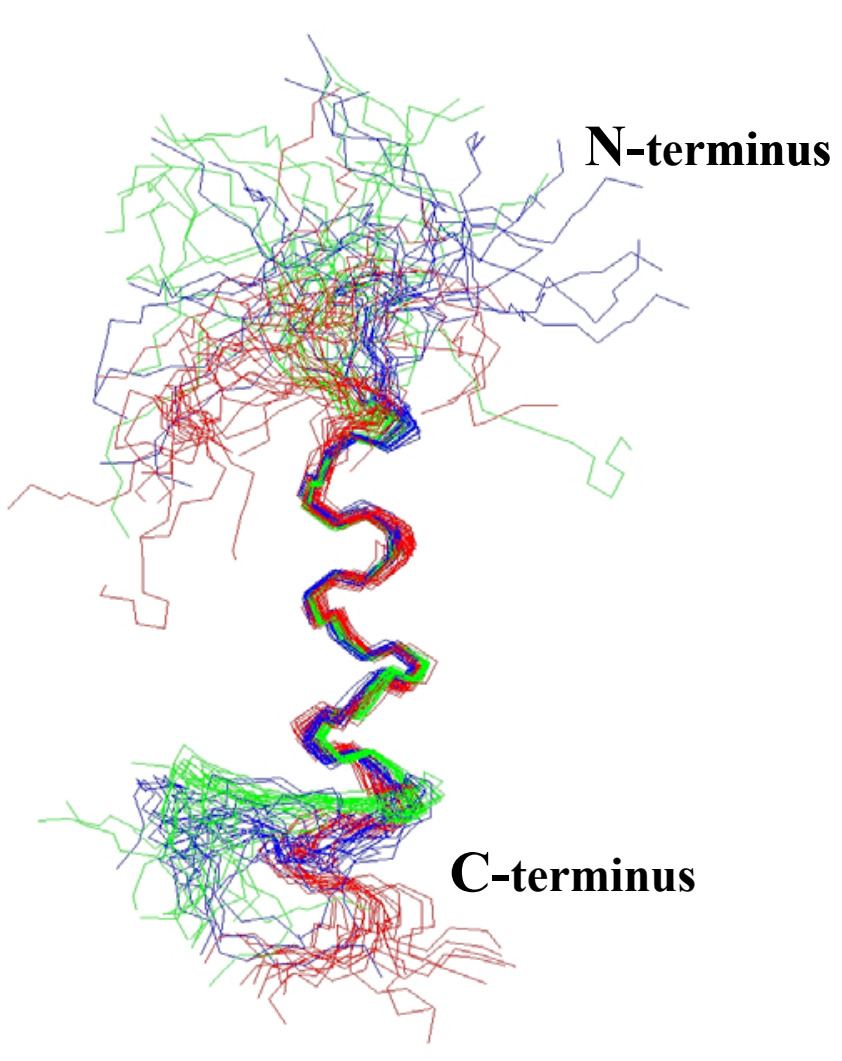

(B)

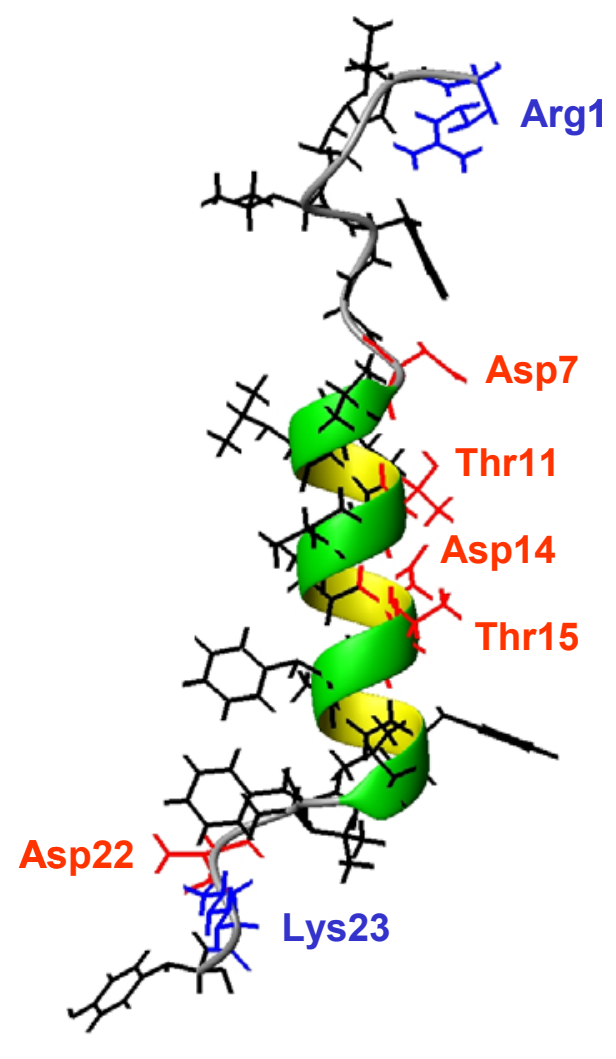


FIGURE 6

pH 4.0

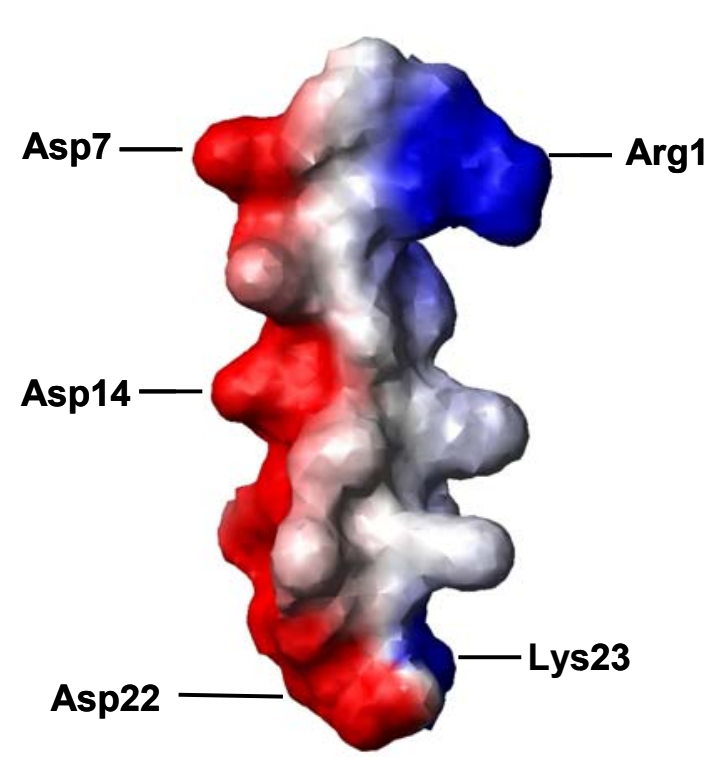

pH 7.4

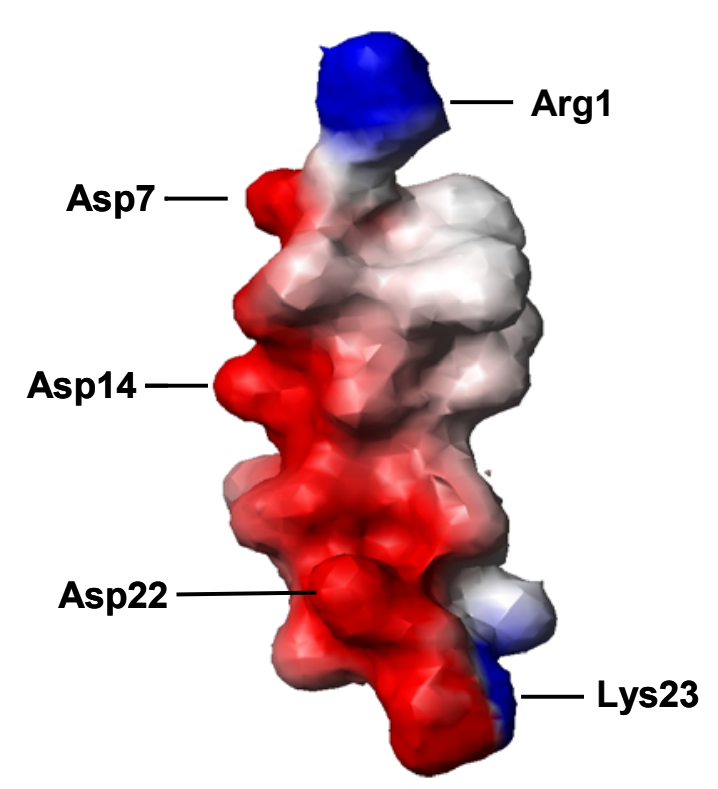




\section{FIGURE 7}

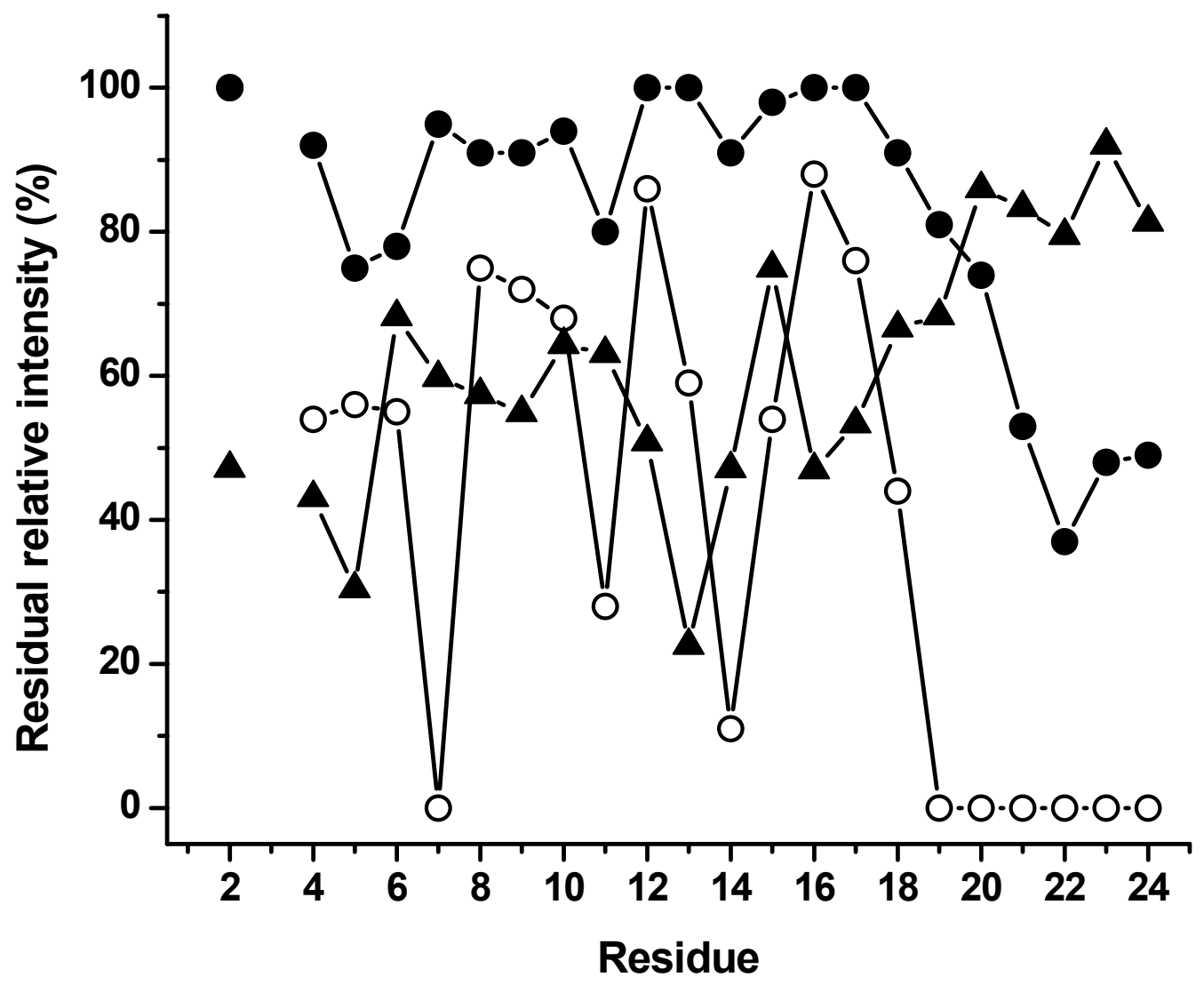


"NMR Structures and Orientation of the Fourth Transmembrane Domain of the Rat Divalent Metal Transporter (DMT1) with G185D Mutation in SDS Micelles" by H. Li et al

FIGURE S1 Differences between $\mathrm{H}^{\alpha}$ and $\mathrm{H}^{\mathrm{N}}$ chemical shifts of the G185D peptide and the wild-type DMT1-TM4 at pH 4.0 (upper panel) and 7.4 (lower panel).
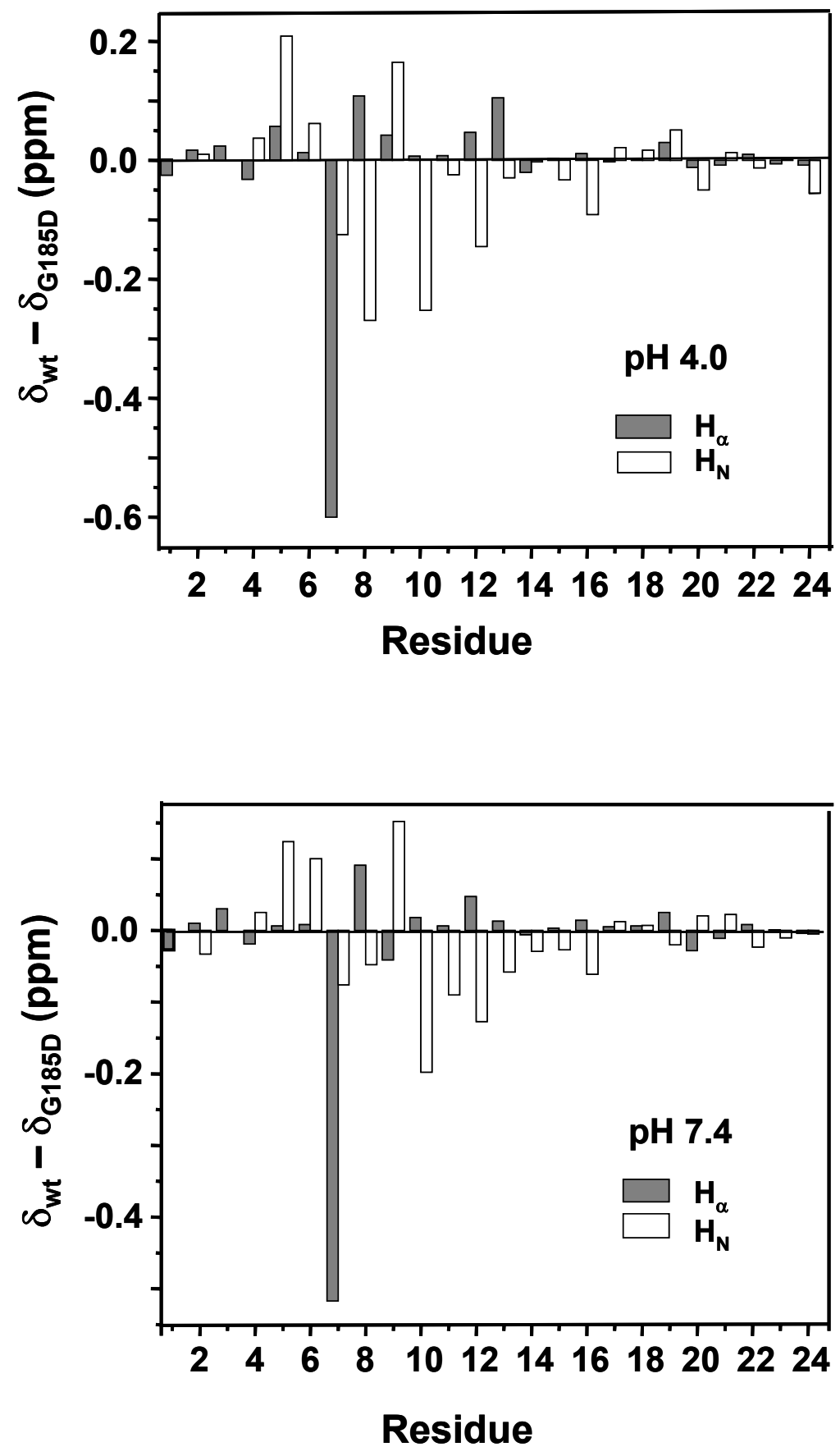
FIGURE S2 DOSY spectrum of the G185D peptides acquired for diffusion time $(\Delta)$ of $250 \mathrm{~ms}$ in TFE.

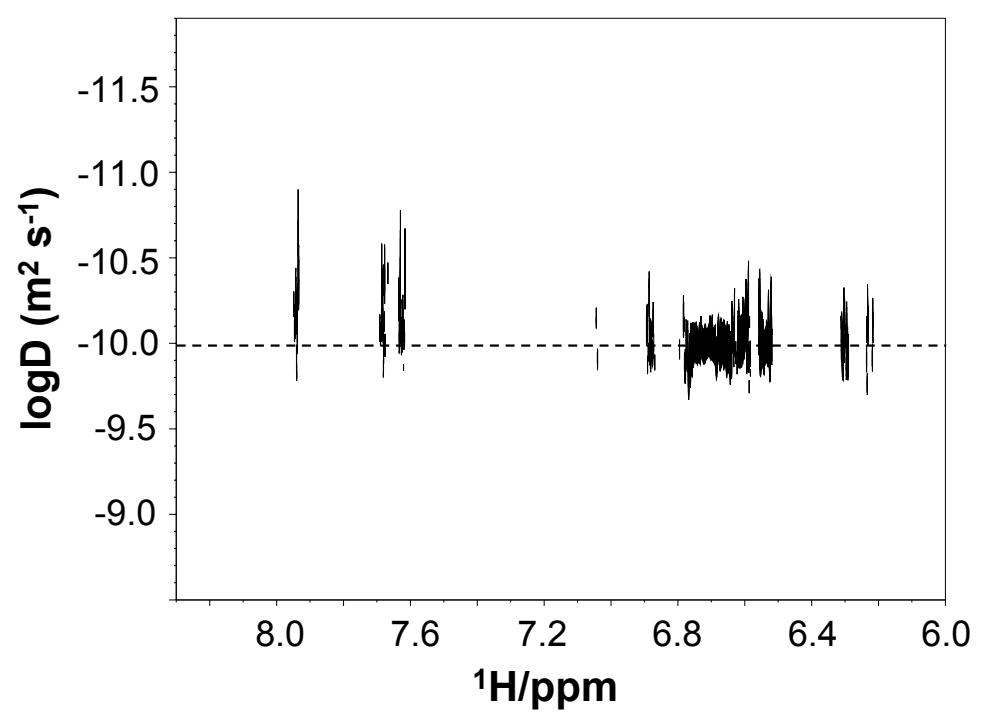

